\title{
Optimal utilization of automated distributed generation in smart grid using genetic algorithm
}

\author{
Ayman Hoballah ${ }^{1}$, Yasser Ahmed ${ }^{2}$, Kamel A. Shoush ${ }^{3}$ \\ 1,2,3 Department of Electrical Engineering, Taif University, Saudi Arabia \\ ${ }^{1}$ Tanta University, Egypt \\ ${ }^{2}$ Electronic Research Institute, Egypt \\ ${ }^{3}$ AL-Azhar University, Egypt
}

\begin{tabular}{l}
\hline \hline Article Info \\
\hline Article history: \\
Received Jan 9, 2019 \\
Revised Apr 11, 2019 \\
Accepted May 8, 2019 \\
\hline
\end{tabular}

Keywords:

Distributed generation (DG), Fuel cell (FC),

Genetic algorithm (GA),

Renewable energy

\begin{abstract}
Distributed generation is an essential attributor in smart grid to fulfill the uncontrollable increase in the demand of energy. Artificial intelligent optimization techniques are widely used within automation systems for guarantee the optimal operation and utilization of DG allocations on the dayahead power scheduling. In this paper, genetic algorithm technique used for obtaining the optimal utilization of the automated operation of distributed generation for power losses and total cost minimization as well as user comfort maximization considering all operating constraints. Distributed generation represented by fuel cell system to supply part of the daily demand in power system. The target is to apply decision-making strategy of smart operation for economical and reliable operation of power system. Concentrated fuel cell units considered at the load centers. The methodology applied on 11-buss test system. The simulation results have demonstrated that the GA capability for full automation of DGs in smart manner within power system for economic and safe operation. The total daily operating cost and power losses reduced.
\end{abstract}

Copyright $@ 2019$ Institute of Advanced Engineering and Science. All rights reserved.

\section{Corresponding Author:}

Ayman Hoballah,

Department of Electrical Engineering,

Taif University, Saudi Arabia.

Email: ayman.h@tu.edu.sa

\section{INTRODUCTION}

The modern control schemes facilitates the extensive integration of distributed generators (DG) in electric power system. The integration accomplished by continuous on/off switching process of control devices for monitoring and control, which can be achieved by different types of programmable microcontrollers[1]-[2]. This involves the presence of two-way energy flow across the smart deregulated power system due to the spread of using DG for maximize user comfort at minimum operating cost and power losses [3]-[4]. In addition to the uncertainty associated with electric demand, uncertainty associated with available level of generated power from DG units presents more challenges in deregulated power operation where the consumers have the opportunity to integrate DG units in power system [5][6]. Therefore, it is important to consider an automated control methodology for intelligent economical operation of deregulated power system compromising DG units' output power availability and load fluctuations [7]-[8]. Different artificial intelligent techniques such as genetic algorisms, particle swam, hybrid bacterial foraging, and firefly optimization techniques can be used to handle the search for optimal solution for economic operation [9]-[10]. The solution should balance the power demand and the available power generations from DGs and network considering all operating constraints of all variables in the power system [11]. To achieve this goal, the energy flow between these units and the entire power system should be controlled via central control in a simultaneous manner to satisfy all demands and achieve an accepted economic profit for both 
consumers and grid operators [12][13]. The fuel cell system (FC) technologies are rapidly increasing the output power and large-scale fuel cell integrations in power system are expected in the future and used in this study [14][15].

In this paper, the problem is formulated as constrained optimization problem to make deep searching on the DG units automation for economic operation of electric power system. large-scale fuel cell system integration considered as DG and the main target is to investigate the impacts of integration on dayahead power generation. The objective function supposed to contain all relative operating costs of fuel cell groups (start and stop cost, import and export energy costs, maintenance costs...) and all terms that affect the optimal settings of DG units and power flow. Genetic algorithm optimization technique is used to obtain the optimal hourly generation levels for economic operation considering all operating constraints. The loads are considered as load centers where each one contains different characteristics of two FC units and connected to the grid for electric energy exchange. Pre-collected data related to the forecasted daily electric loads are send in advance to the control center via supervisory control and data acquisition system (SCDA) where the optimization process is performed in order to determine the optimal operating on/off settings of all FC units.

\section{RESEARCH METHOD}

\subsection{Objective Function Formulation}

The objective problem formulated as total daily operating cost minimization problem. The target is to minimize the total cost of power generation $\left(F_{t}\right)$ from FC systems and generators to supply daily load considering power flow constraints [11], [16]. The cost function includes any costs related to FC systems operation and the cost of purchased power from the grid to supply the all daily loads. Any possible feeding the grid by the excess power from load centers will reduce the daily payments. Genetic optimization algorithm used to specify the optimal on/off settings of FCs that minimize the total daily operating cost of generation. The power flow at each operating point used to investigate all power system operating constraints during optimization process. The objective function $\left(F_{t}\right)$ represents can be formulated by (1-4) as follows:

Minimize,

$$
F_{t}=\sum_{i=1}^{24} \sum_{j=1}^{N}\left(C_{F C}^{j}+C_{\text {purchase }}^{j}-C_{\text {sold }}^{j}\right)
$$

Subject to load flow constraints,

$$
\begin{aligned}
& \sum_{i=1}^{24}\left(P_{F C}+P_{\text {Grid }}\right)=\sum_{i=1}^{24}\left(P_{\text {load }}+P_{\text {loss }}\right) \\
& V_{\text {bus }}^{\text {min }}>V_{\text {bus }}>V_{\text {bus }}^{\max } \\
& S_{\text {flow }}^{\text {min }}>S_{\text {flow }}>S_{\text {flow }}^{\text {max }}
\end{aligned}
$$

Where, $C_{F C}$ is the total costs of fuel cells including the daily natural gas, start-up, maintenance, and operating costs. $C_{\text {purchase }}$ and $C_{\text {sold }}$ are the cost of purchased and sold electricity respectively from each load center. $\mathrm{N}$ is the number of FC systems.

The GA optimization used to obtain the optimal on/off settings of the FC units to contribute the supply of the daily load center's needs maintaining low operating cost and satisfying power flow constraints. The power flow and FCs operating constraints are considered utilizing self-adaptive penalization by constructing a refined objective function $\left(F_{t, i}^{r e f}\right)$ using the normalized cost function $\left(F_{t, i}^{n}\right)$ and average normalized constraints violation rates $\left(\operatorname{Con}_{e q, i}^{\mathrm{Vio}}\right)$. The refined (normalized) objective function used to penalize the infeasible solutions for considering the constraints violations can be formulated by (5) [17]:

$$
F_{t, i}^{r e f}=\sqrt{\left(k_{1}\right)\left(F_{t, i}^{n}\right)^{2}+\left(\operatorname{Con}_{e q, i}^{\text {Vio }}\right)^{2}}+\left(1-D_{f}\right) *\left(k_{1}\right) * \operatorname{Con}_{e q, i}^{\text {Vio }}+k_{2} * D_{f} * F_{t, i}^{n}
$$

where, $D_{f}$ is the percentage of feasible solutions in swarm respectively. $\operatorname{Con}_{e q}^{\text {Vio }}$ is the average normalized constraint violations of the particle, $k_{1}$ equals zero with no feasible solutions in the swarm, $k_{2}$ equals zero when the particle, $i$, is feasible solution.

The optimal on/off settings of FCs send to the units control system through the SCAD system. Each load center pays the cost of required natural gas (NG) needed for the FC operation, maintenance and startup

Optimal utilization of automated distributed generation in smart grid using genetic... (Ayman Hoballah) 
costs of FCs and the cost of purchased electricity from the grid or neighboring load centers. The only income is from the sold electricity to the network when excess power between the consumed power and the generated power from FC system is available. The main steps that are used to implement the on/off settings of FC operation for optimal power flow at minimum operating cost can be summarized as follow:

a. Preparing all required data for power system simulation including modelling and current state of operation of all equipment.

b. Forecast the daily load curve for all loads based on the historical data.

c. Specifying the operating on/off conditions of the FCs, their characteristics and technical data.

d. Determine the expected energy costs including the price of electricity and NG trading.

e. Operate the constrained optimization technique based genetic algorithm to solve the optimal power flow for the daily load at minimum total operating costs. The considered constraints during optimization process are the flow limits such as voltage profiles, transmission lines power, generation levels and FC system constraints.

f. Send the obtained sequential operating settings of all generating units and FCs to units' controllers through the control center communications.

g. Continuous adjustment of the optimal solution to modify the operating point based on the actual hourly load and system operating conditions to account the uncertainty of load forecasting.

\subsection{GA Optimization Technique}

GA is widely used heuristic optimization technique to search for the optimal solution (best individual) based on iterative evolutionary operating process. GA is a prevalent metaheuristic algorithm that belongs to an algorithms group known as evolutionary algorithms. GA depends on the method of natural selection, crossover and mutation. GA used to find the optimal solutions that optimize the operation of the system under different operating conditions. The individuals evaluated iteratively based on the fitness function where the best ones remain and others modified until one of the stopping conditions is satisfied. The natural selection process selects fittest individuals from the population. The fittest inherit the parent's properties, which transferred to the next generation (offspring), if parents have better physical fitness (chromosomes update), the offsprings may be better and have good chance for surviving during the iterative process. The selection process continues to repeat. At the end, generation with the best individuals created and the best one selected as optimal solution.

Figure presents a flow chart for the main steps of GA optimization technique. The steps summarized as follow:

a. Initial population: Select the initial population (active power generated by generating units and FC system generation levels) of individuals randomly from the set defined by the minimum and maximum valued of generated power

b. Fitness function: Each individual assessed in the population in terms of objective function. In this study, the objective function defined by the total daily operating cost to supply the load power, which obtained from optimal power flow calculations.

c. Stopping Criteria: Check for the required conditions for stopping, if compiled stop, otherwise go to the next step in the iterative process.

d. Selection: From the given population, the individuals ranked based on the objective function and the ones with high fitness are selected pass to the next step for crossover.

e. Crossover: This process used to produce new population of individuals (offsprings) by modifying the selected ones in the previous step using the genetic characteristics of parents based on one of the developed crossover strategies.

f. Mutation: Operation take placed on the new population to generate new generation of particles to keep the diversity of the generations for discovering new search area and avoiding local minima in the final solution.

g. Best Solution: The more fit individuals selected statistically to form new population replacing the current population in the next step of optimization. The best solution stored and the iterative process continued until the maximum no of iteration reaches or stopping criteria satisfied.

The convergence of GA optimization algorithm strongly depend s on the parameters of selection, crossover and mutation processes, which depend on the problem under investigation. These parameters obtained by trial and error to accelerate the convergence of optimization process towards the global best solution based on the problem under investigation. The parameters of GA optimization algorithm used during this iterative process summarized in Table 1. 


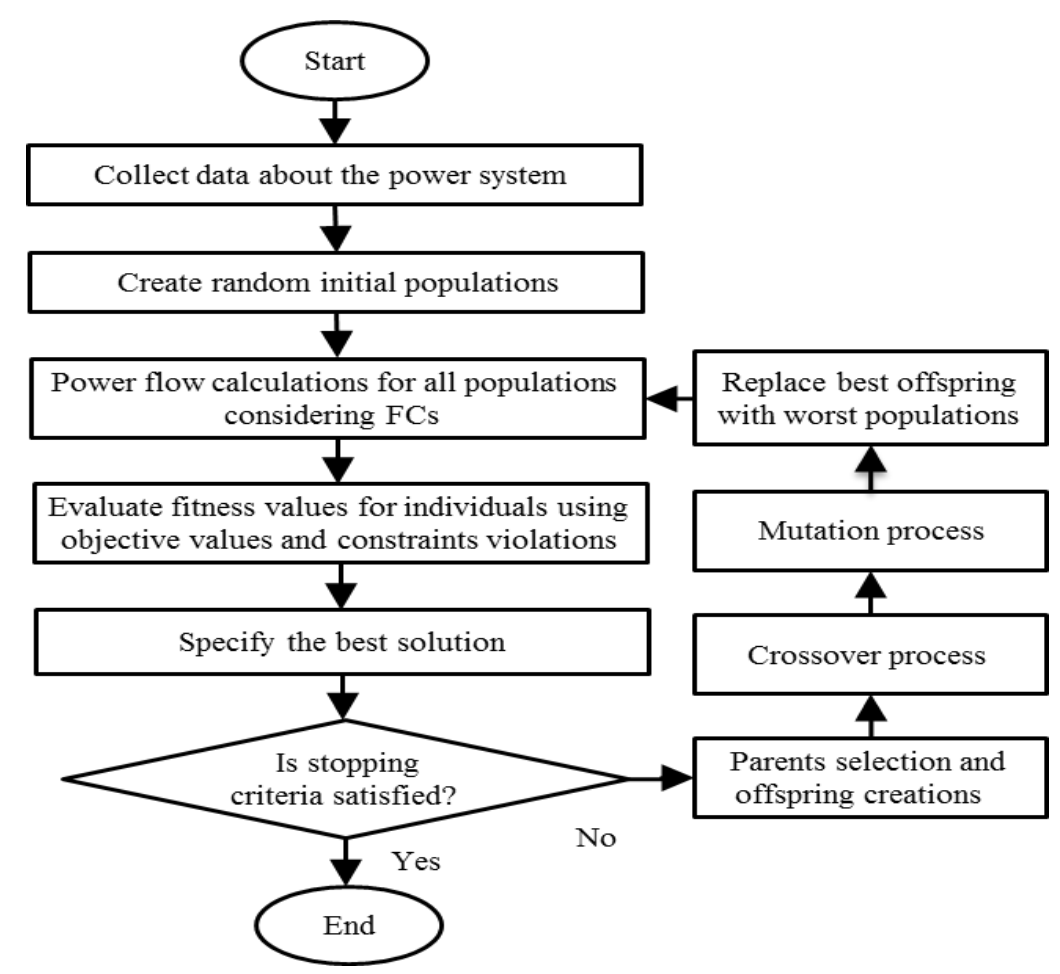

Figure 1. The main steps of GA optimization technique

Table 1. The Parameters of GA Optimization Algorithm

\begin{tabular}{cccc}
\hline Name & Value & Name & Value \\
\hline Maximum Number of Iterations & 2000 & Mutation Percentage & 0.06 \\
Size of Population & 30 & Mutation Rate & 0.02 \\
Crossover Percentage & 0.9 & & \\
\hline
\end{tabular}

\subsection{Test System Description}

The application of the GA for automated operation of FC system operation in daily power flow is adapted in Matlab environment using 11-Bus test system. Figure 2 presents the schematic diagram for the main system components [18][18]. The system contains two similar areas with four conventional generators, two load centers and eight transmission lines. The FCs considered as four equivalent groups connected at the two load centers. Each group consists of many fuel cells with similar characteristics. The test system modified by adding the four groups of FCs at two load centers. All synchronous generating stations considered identical where each station consists of five units with 247 MVA rating except the slack bus with six generating units and has excitation and governing systems for output power control.

Figure presents the forecasted daily active power of loads. The target is to specify the scheduling of demand among all four thermal generating stations in addition to the four FCs in an economical manner. The required reactive power supplied by the thermal generating stations at voltage controlled busses which integrated by excitation systems.

The objective is the minimization of the total daily operating cost of supplied power to load centers within the smart deregulated system considering different operating constraints. At the first stage, the system operator at control center supposes to collect the energy bids from generators, daily forecasted load and technical data related to FC characteristics and transmission system as shown in

Figure . The control variable (generated power from energy sources) and all constraints represent optimization problem, which can be solved GA optimization technique. The time step taken as one hour for simplification and the process can be applied for different duty time. The second stage is the collection of the network and FCs characteristics as well as specifying the system operating constraints and associated prices. FC groups can feed part of the demand at each load center while the remaining load obtained from the grid 
according to the pre-specified price. Each load center connected to the network through smart meter where the smart meters count the purchased or sold power from the network.

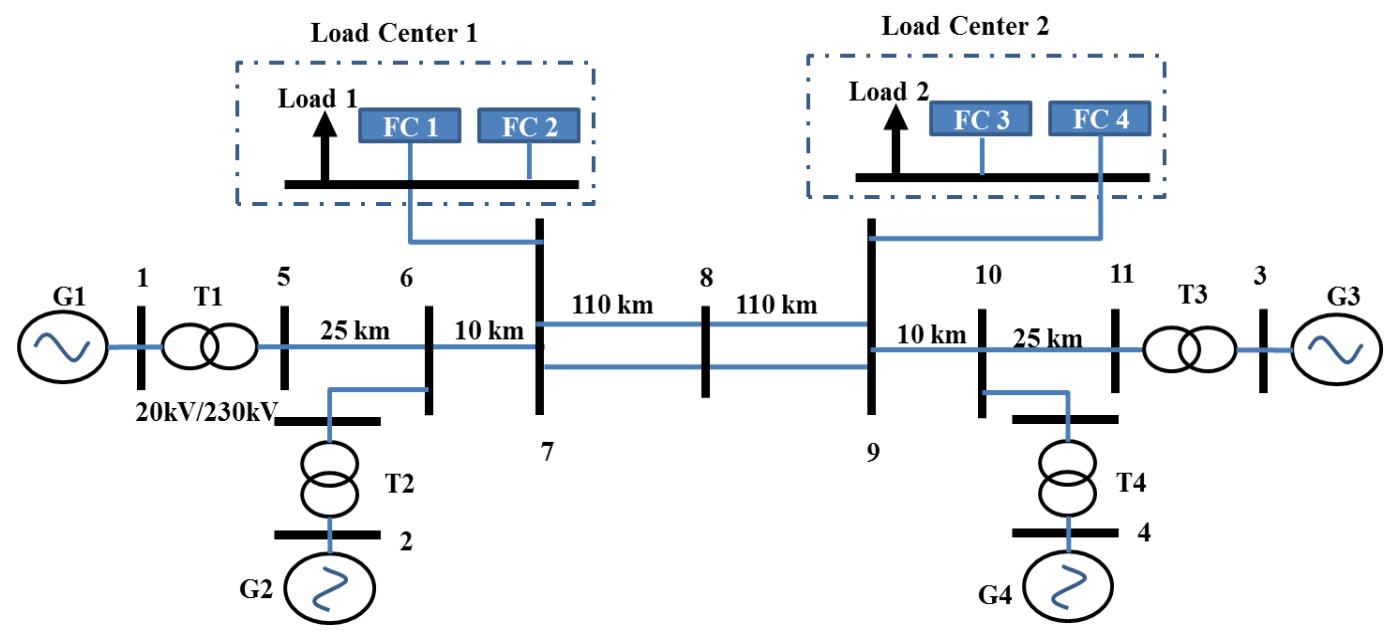

Figure 2. A modified 11-Bus test system of two similar areas

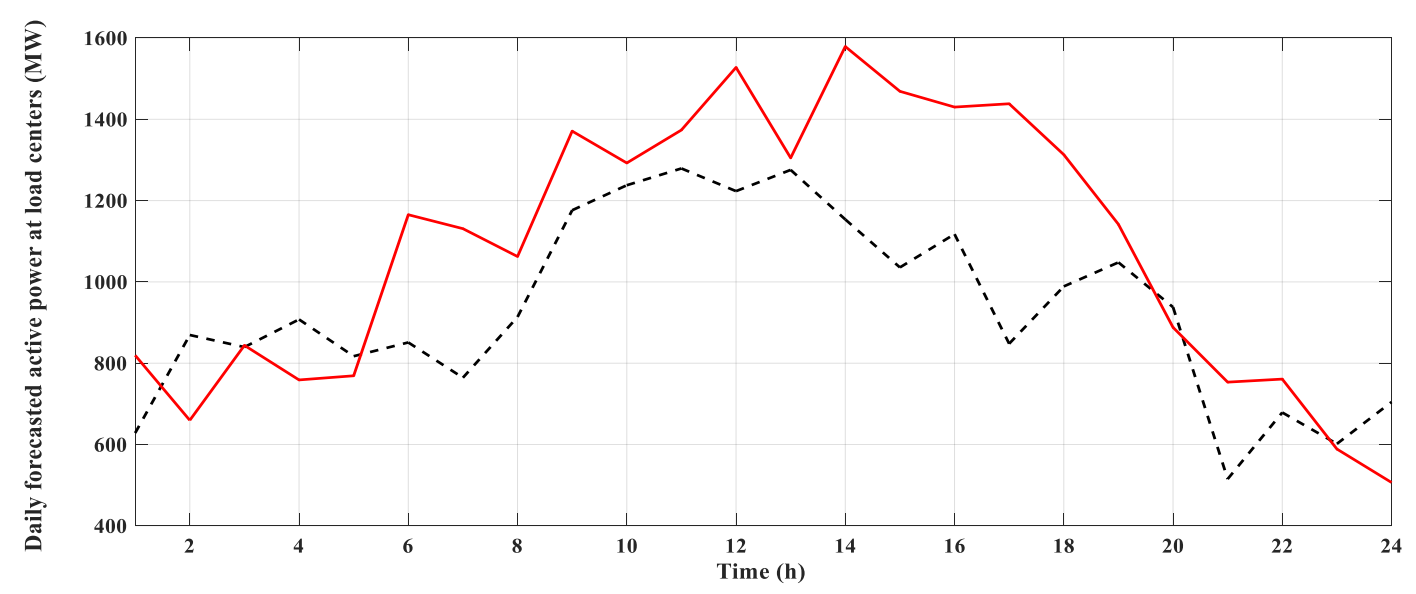

Figure 3. Daily forecasted active power of loads

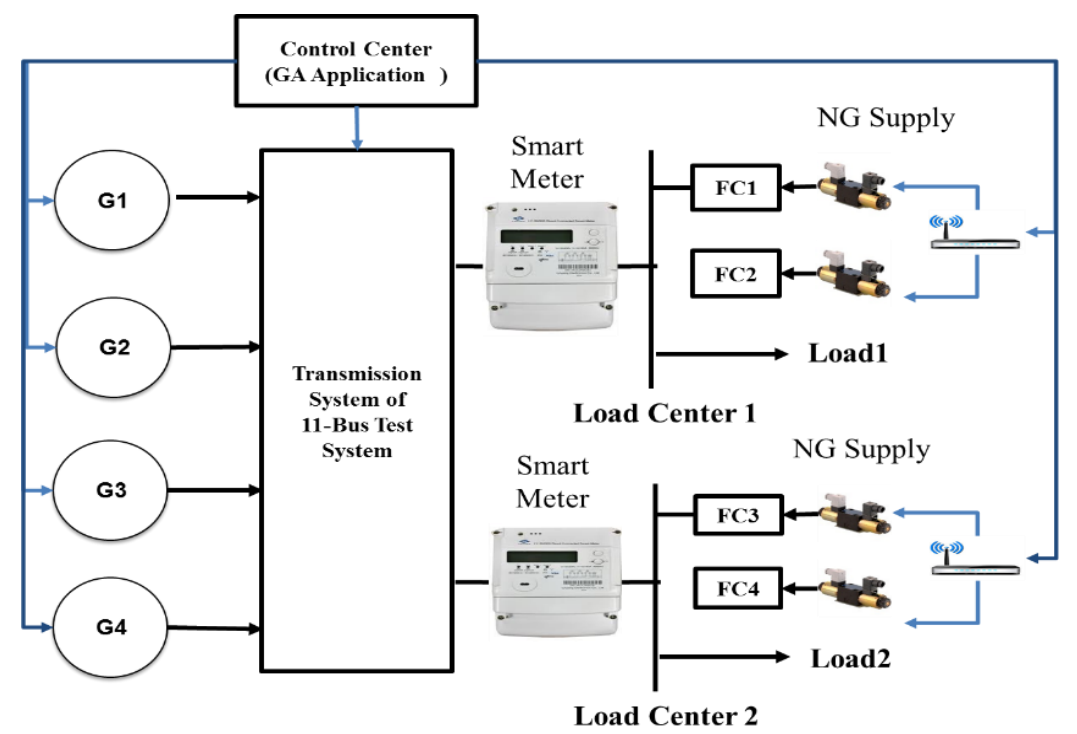

Indonesian J Elec Eng \& Comp Sci, Vol. 16, No. 1, October 2019 : 82 - 91 
Figure 4. Schematic diagram of system configuration

Thus, GA applied to solve the optimization problem to catch the optimal operating states and generation levels from FCs for total cost minimization. The fitness function formulated as a constrained objective function based on the operating cost and system constraints violations.

\subsection{Fuel Cell System}

FC system is an electrochemical reaction based system that utilizes the generated electrons during chemical reaction into electricity in addition to thermal energy. The extensively used FC systems are proton exchange membrane fuel cell (PEMFC) due to its high power density and fast response. PEMFC contains a porous anode, a porous cathode, and a polymer electrolyte membrane. The electrolyte should be efficiently able to conduct protons from anode to cathode [19][20]. The schematic diagram of simplified FC unit presented in

Figure.

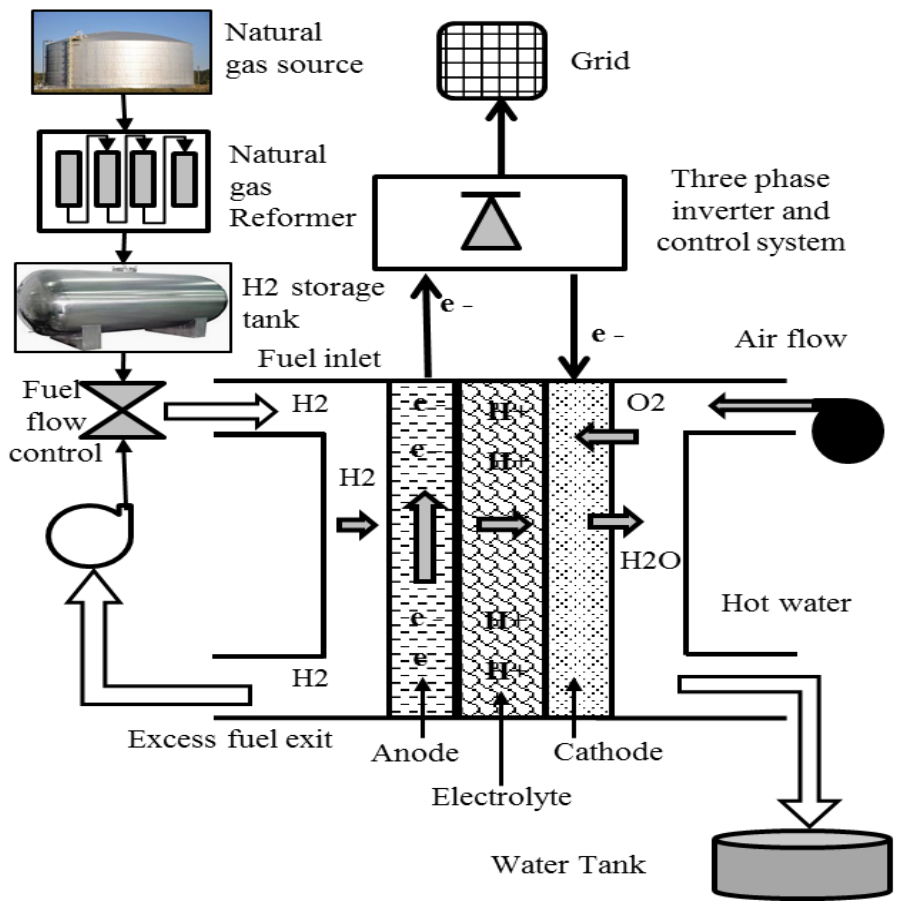

Figure 5. Schematic diagram of FC unit

The FC unit considered as power-only system fueled by hydrogen. When the hydrogen pumped through the anode, it ionizes releasing electrons and produces $\mathrm{H}+$ ions (protons) which flow through electrolyte (Polymer) as in (1). Released electrons move through external electric circuit towards the cathode. At the cathode side, pumped oxygen combines with the electrons and protons to form water and released heat as in (6-8). The overall reaction concluded where the inputs are hydrogen and oxygen and the outputs are water, electricity and heat [21][22].

$$
\begin{aligned}
& 2 \mathrm{H}_{2} \rightarrow 4 \mathrm{H}^{+}+4 e^{-} \\
& \mathrm{O}_{2}+4 \mathrm{H}^{+}+4 e^{-} \rightarrow 2 \mathrm{H}_{2} \mathrm{O} \\
& \mathrm{H}_{2}+\frac{1}{2 \mathrm{O}_{2}} \rightarrow \mathrm{H}_{2} \mathrm{O}+\text { electricity }+ \text { heat }
\end{aligned}
$$

There are many methods can be used to produce the required hydrogen for FC operation such as reformation of natural gas, reformation of hydrocarbons, gasification of coal and partial oxidation of heavy crude oils [22]. 


\section{RESULTS AND DISCUSSION}

The problem formulated as constrained optimization problem where the power flow constrains considered during iterative solution of power flow at each operating point. The available ratings of FC groups at load center 1 are 200 and $150 \mathrm{MW}$ while 150 and $100 \mathrm{MW}$ presented at load center 2 . Table 2 summarizes the prices and main parameters of the used four FCs groups. The used FC represented in equivalent four groups where the efficiencies of FC1 and FC2 groups presented in

Figure and the efficiencies of FC3 and FC4 groups presented in Error! Reference source not found. [9], [11].

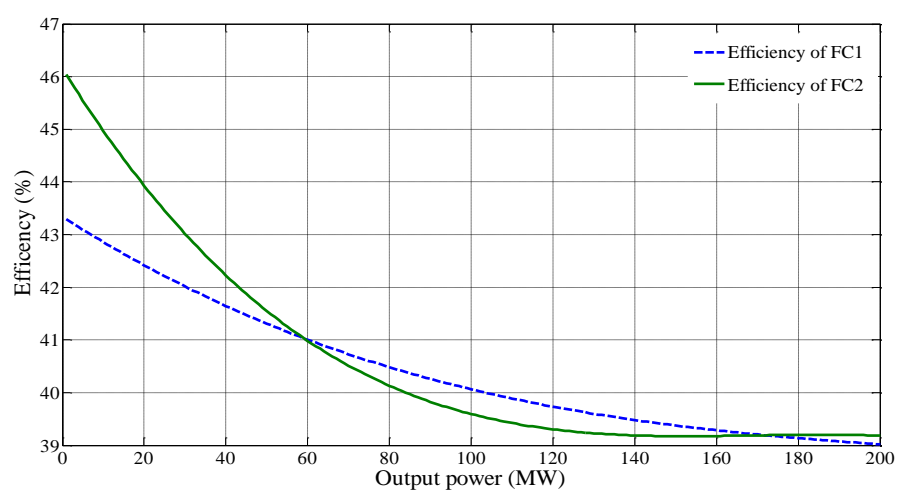

Figure 6. The efficiency of FC1 and FC2 groups

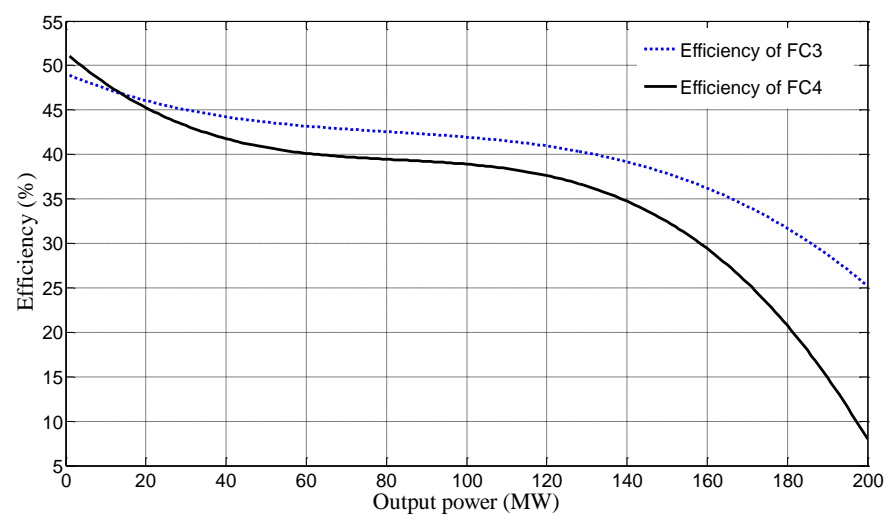

Figure 7. The efficiency of FC3 and FC4 groups

Table 1. The Parameters of the Used Four FC Groups and Prices

\begin{tabular}{lcccc}
\hline \multicolumn{1}{c}{ Parameter } & FC1 & FC2 & FC3 & FC4 \\
\hline Rating of equivalent FC system in each group (MW) & 200 & 150 & 150 & 100 \\
Maximum up ramp rates of group (kW/Dt) & 150 & 100 & 100 & 100 \\
Maximum down ramp rates of group (kW/h) & 100 & 75 & 75 & 75 \\
Minimum allowed up times of group (h) & 4 & 4 & 3 & 3 \\
Minimum allowed down times of group (h) & 2 & 2 & 1 & 1 \\
Cooling time constant of group (h) & 0.5 & 0.48 & 0.47 & 0.43 \\
Hot start-up cost of each FC (\$) & 0.04 & 0.03 & 0.03 & 0.026 \\
Cold start-up cost of each FC (\$) & 0.35 & 0.3 & 0.25 & 0.2 \\
Price of natural gas (\$/kWh) & & & 0.07 & \\
Price of purchase electricity from network $(\$ / \mathrm{kWh})$ & & 0.18 & \\
Price of soled electricity to network $(\$ / \mathrm{kWh})$ & & 0.13 & \\
Operating and maintenance cost $(\$ / \mathrm{kWh})$ & & & & \\
\hline
\end{tabular}


Table 3 presents the generated power from each generator, generated power from each FC system, the hourly forecasted load at each load center and corresponding power losses. Figure 8 presents daily supplied power from FCs. The variation of total cost minimization during iterative process using GA optimization technique presented in Figure 9. Based on the used price of purchasing electricity $0.18 \$ / \mathrm{kWh}$, the total daily operating cost is 10241.09 \$day where the total daily operating cost utilizing FCs integration using GA reduced to 8650 \$/day. The daily saving with using the FC systems is 1591.09 \$/day. In addition to the reduction of the total daily operating cost, the local supplying of part of load by FC systems reduce the system daily power losses from 302.35 MW to 245.975 MW.

Table 3. The Generated Power from Generstors, FC Systems and Loads (MW)

\begin{tabular}{|c|c|c|c|c|c|c|c|c|c|c|c|c|c|c|c|}
\hline & Pg1 & Pg2 & Pg3 & $\mathrm{Pg} 4$ & Pgt & FC1 & FC2 & FC3 & FC4 & FCt & Total G & PI1 & $\mathrm{PI} 2$ & Plt & Ploss \\
\hline 1 & 141 & 193.2 & 101.7 & 791.9 & 1227.8 & 63.7 & 46.3 & 90.9 & 26.6 & 228 & 1455 & 819.40 & 628.3 & 1447.7 & 7.60 \\
\hline 2 & 617.5 & 134 & 457.6 & 100 & 1309.1 & 51.6 & 61.3 & 83.9 & 28.1 & 225 & 1534 & 659.60 & 869.4 & 1529.0 & 5.00 \\
\hline 3 & 683.3 & 525.3 & 138.7 & 127.7 & 1475.0 & 66.4 & 39.7 & 79.4 & 32 & 218 & 1693 & 843.90 & 839.7 & 1683.6 & 8.90 \\
\hline 4 & 18.9 & 138.3 & 896.3 & 418.2 & 1471.7 & 51.9 & 38.2 & 85.1 & 28.6 & 204 & 1676 & 758.90 & 907.7 & 1666.6 & 8.90 \\
\hline 5 & 333.3 & 828.9 & 119.4 & 100 & 1381.6 & 46.1 & 41.5 & 97.9 & 26.4 & 212 & 1594 & 769.10 & 817.2 & 1586.3 & 7.20 \\
\hline 6 & 359.5 & 994.6 & 345.3 & 100 & 1799.4 & 66.7 & 31.5 & 100 & 26.1 & 224 & 2024 & 1165.20 & 851.1 & 2016.3 & 7.40 \\
\hline 7 & 157.2 & 815.1 & 100 & 611.1 & 1683.4 & 57.4 & 42.4 & 91.2 & 27.2 & 218 & 1902 & 1131.00 & 764.3 & 1895.3 & 6.30 \\
\hline 8 & 1152.9 & 428.7 & 100 & 100 & 1781.6 & 58.1 & 40.5 & 87.8 & 25.8 & 212 & 1994 & 1062.40 & 913.7 & 1976.1 & 17.70 \\
\hline 9 & 757.1 & 679.8 & 504.9 & 400.8 & 2342.6 & 62.1 & 43 & 87.5 & 23.6 & 216 & 2559 & 1370.90 & 1176.3 & 2547.2 & 11.60 \\
\hline 10 & 1300.2 & 306.3 & 378.2 & 329.6 & 2314.3 & 50.2 & 58.4 & 97.4 & 29.4 & 235 & 2550 & 1292.50 & 1237.8 & 2530.3 & 19.40 \\
\hline 11 & 1347.6 & 100 & 344.3 & 683.6 & 2475.5 & 41.7 & 39.7 & 89.5 & 26.9 & 198 & 2673 & 1373.60 & 1279.1 & 2652.7 & 20.60 \\
\hline 12 & 1443.7 & 669.6 & 100 & 330.6 & 2543.9 & 71.7 & 41.1 & 94 & 28.9 & 236 & 2780 & 1527.60 & 1223.3 & 2750.9 & 28.70 \\
\hline 13 & 294 & 500.3 & 586.7 & 1000 & 2381.0 & 48.2 & 37.8 & 100.6 & 28.9 & 216 & 2597 & 1305.10 & 1275.5 & 2580.6 & 15.9 \\
\hline 14 & 1137.2 & 149 & 360.9 & 868.4 & 2515.5 & 63.3 & 50.1 & 95.6 & 27.6 & 237 & 2752 & 1579.00 & 1153.7 & 2732.7 & 19.4 \\
\hline 15 & 804.6 & 979.8 & 100 & 440.1 & 2324.5 & 44.9 & 43.9 & 84.4 & 22.1 & 195 & 2520 & 1468.80 & 1035.6 & 2504.4 & 15.4 \\
\hline 16 & 565.3 & 936.9 & 631.8 & 212.2 & 2346.2 & 51.9 & 45.9 & 90.6 & 23.3 & 212 & 2558 & 1430.00 & 1117.5 & 2547.5 & 10.4 \\
\hline 17 & 1437.6 & 104.3 & 144 & 413 & 2098.9 & 58.3 & 37.7 & 88 & 22.8 & 207 & 2306 & 1438.20 & 848.0 & 2286.2 & 19.5 \\
\hline 18 & 515 & 265.2 & 1000 & 324.7 & 2104.9 & 54.8 & 38.7 & 91.7 & 23 & 208 & 2313 & 1313.10 & 988.9 & 2302.0 & 11.1 \\
\hline 19 & 413 & 100 & 993.6 & 481.7 & 1988.3 & 55.3 & 40.9 & 93.5 & 24 & 214 & 2202 & 1141.70 & 1048.0 & 2189.7 & 12.3 \\
\hline 20 & 58.3 & 373.8 & 539.8 & 651.9 & 1623.8 & 53.8 & 45.2 & 91.9 & 19.3 & 210 & 1834 & 888.10 & 937.9 & 1826.0 & 8.0 \\
\hline 21 & 274.7 & 353.4 & 114.1 & 321.9 & 1064.1 & 47.7 & 41.1 & 90 & 28.2 & 207 & 1271 & 753.40 & 515.0 & 1268.4 & 2.7 \\
\hline 22 & 448.8 & 109.7 & 436.1 & 222.2 & 1216.8 & 66.4 & 38.9 & 90.1 & 30.8 & 226 & 1443 & 760.90 & 678.8 & 1439.7 & 3.3 \\
\hline 23 & 444.8 & 300.2 & 109.7 & 100 & 954.7 & 67.7 & 51.6 & 98.2 & 21.8 & 239 & 1194 & 588.90 & 601.7 & 1190.6 & 3.4 \\
\hline 24 & 332.5 & 100 & 100 & 474.3 & 1006.8 & 57.4 & 29.9 & 94.7 & 25.5 & 208 & 1214 & 506.60 & 704.5 & 1211.1 & 3.2 \\
\hline Total & & & & & 43431.4 & & & & & 5203.4 & 48634.8 & & & 48360.9 & 273.9 \\
\hline
\end{tabular}

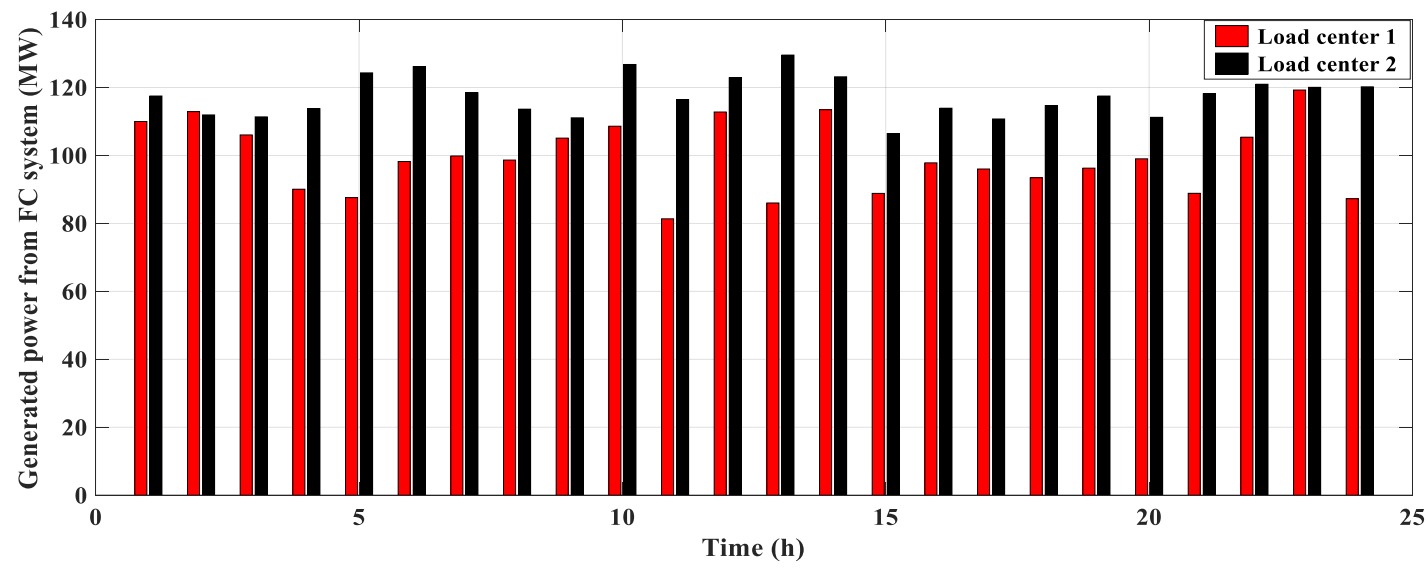

Figure 8 . The daily supplied power from FC groups 


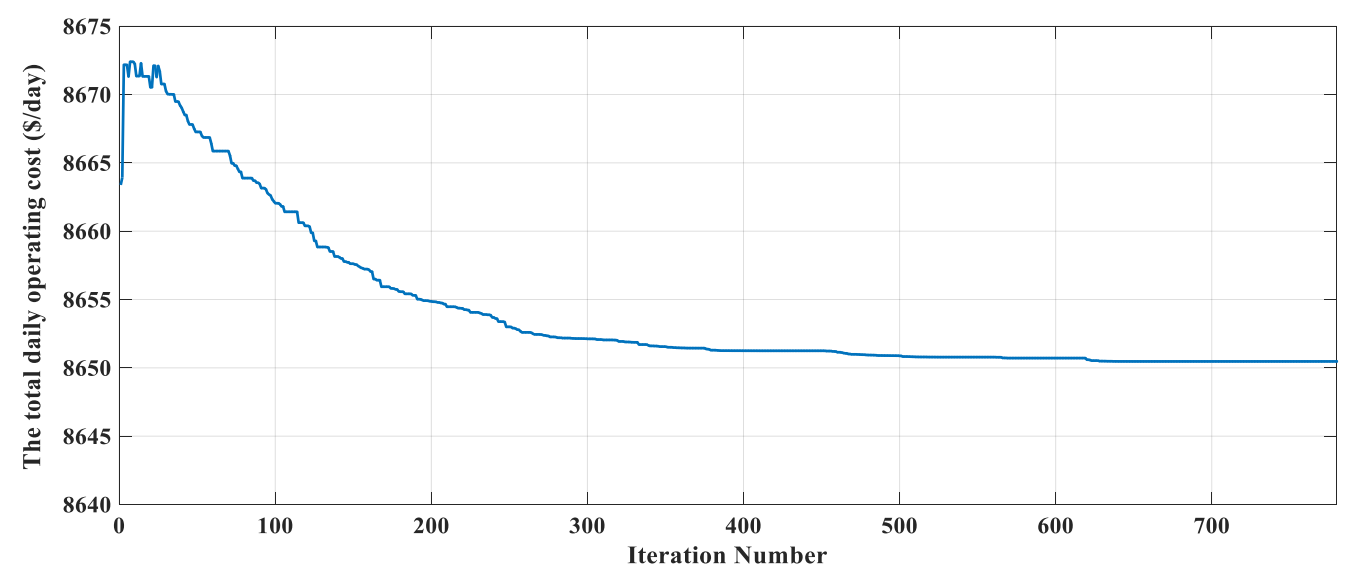

Figure 9. The total daily operating cost variation during iterative process

\section{CONCLUSION}

The GA used as an optimization technique to solve the daily on/off settings of FCs to minimize the operating cost considering power system constraints. The results prove that the selection of optimal on/off settings of FCs lead to minimize the total daily operating cost as well as the system losses considering all system constraints. The optimization process requires time for simulation and not suitable for online application due to solving the power flow problem so many to reach the optimal solution. The time consumption will increase with considering the system dynamic stability constraints

\section{ACKNOWLEDGEMENT}

This work was supported by Taif University under the serial number of 5896-438-1

\section{REFERENCES}

[1] F. Ponci, A. Sadu, R. Uhl, M. Mirz, A. Angioni and A. Monti, "Instrumentation and measurement testing in the real-time lab for automation of complex power systems," in IEEE Instrumentation \& Measurement Magazine, vol. 21, no. 1, pp. 17-24, February 2018.

[2] A. Angioni et al, "Design and Implementation of a Substation Automation Unit," in IEEE Transactions on Power Delivery, vol. 32, no. 2, pp. 1133-1142, April 2017.

[3] A. Heidari et al., "Reliability Optimization of Automated Distribution Networks With Probability Customer Interruption Cost Model in the Presence of DG Units," in IEEE Transactions on Smart Grid, vol. 8, no. 1, pp. 305-315, Jan. 2017.

[4] Muhtazaruddin, M.N.B., Bani, N.A., Aris, S.A.M., Kaidi, H.M., Fatah, A.Y.A., Jamia, J.J., Muhammad-Sukki, F. and Abu-Bakar, S.H. "Distribution power loss minimization via distributed generation, capacitor and network reconfiguration”, Indonesian Journal of Electrical Engineering and Computer Science (IJEECS), 2017, 5(3), pp 488-495.

[5] Ajenikoko GA, Olabode OE. "Optimal Power Flow with Reactive Power Compensation for Cost and Loss Minimization on Nigerian Power Grid System", Indonesian Journal of Electrical Engineering and Informatics. 2017; 5(3): 236-247.

[6] Zhipeng Liu; Fushuan Wen; Ledwich, G., "Optimal Siting and Sizing of Distributed Generators in Distribution Systems Considering Uncertainties," Power Delivery, IEEE Transactions on , vol.26, no.4, pp.2541,2551, Oct. 2011.

[7] Ameli, A; Bahrami, S.; Khazaeli, F.; Haghifam, M.-R., "A Multiobjective Particle Swarm Optimization for Sizing and Placement of DGs from DG Owner's and Distribution Company's Viewpoints," Power Delivery, IEEE Transactions on, vol.29, no.4, pp.1831, 1840, Aug. 2014.

[8] Muhamad Najib Kamarudin, Tengku Juhana Tengku Hashim, AbdulHamid Musa," Optimal sizing and location of distributed generation for loss minimization using firefly algorithm”, Indonesian Journal of Electrical Engineering and Computer Science (IJEECS) Vol. 14, No. 1, April 2019, pp. 421-427.

[9] Lidula NWA, Rajapakse AD. "Microgrids research: a review of experimental microgrids and test systems", Renewable and Sustainable Energy Reviews 2011; Vol. 15, pp. 186-20.

[10] Prabha, D. R.; Mageshvaran, R.; Raghunath, E.; Raghuram, G., "Determining the optimal location and sizing of distributed generation Unit using Particle Swarm Optimization algorithm," Computer Communication and Informatics (ICCCI), 2012 International Conference on, vol., no., pp.1,7, 10-12 Jan. 2012. 
[11] Elkazaz, M. H., Hoballah, Ayman, and Azmy, A. M. (2016),"Artificial intelligent-based optimization of automated home energy management systems", Int. Trans. Electr. Energ. Syst., 26: 2038-2056.

[12] Apparao, K. Bhashna, "Optimal Allocation of DG Considering Loss Minimization and Voltage Profile Using PSO", Int. Journal of Science and Research, vol. 4, no. 9, pp. 659-663, 2015.

[13] Gareth P Harrison, Antonio Piccolo, Pierluigi Siano, "A Robin Wallace: Distributed Generation Capacity Evaluation using Combined Genetic Algorithm and OPF", Int. Journal of Emerging Electrical Power Systems, vol. 8, no. 2, 2007.

[14] Dodds PE and Ekins P, " A portfolio of powertrains for the UK: An energy systems analysis", International Journal of Hydrogen Energy, 39(26): 13941-13953. 2014.

[15] Xing Zhang; Current status of stationary fuel cells for coal power generation, Clean Energy, Volume 2, Issue 2, 29 October 2018, Pages 126-139.

[16] M. H. Elkazaz, A. A. Hoballah, A. M. Azmy, "Operation optimization of distributed generation using artificial intelligent techniques", Shams Engineering Journal, vol. 7, pp. 855-866, 2016.

[17] A. Hoballah and I. Erlich, "PSO-ANN approach for transient stability constrained economic power generation," 2009 IEEE Bucharest PowerTech, Bucharest, 2009, pp. 1-6.

[18] P. Kundur. "Power System Stability and Control". New York, NY: McGraw-Hill, 1994, p. 813.

[19] Jiao K, Ni M.,"Challenges and opportunities in modelling of proton exchange membrane fuel cells (PEMFC) ", Int. J Energy Res. 2017, 41, pp 1793-1797. https://doi.org/10.1002/er.3798.

[20] Sujit Kumar Bhuyan, Prakash Kumar Hota, and Bhagabat Panda, "Modeling, Control and Power Management Strategy of a Grid connected Hybrid Energy System, Indonesian Journal of Electrical Engineering and Computer Science (IJECE), Vol. 8, No. 3, June, 2018, pp. 1345-1356.

[21] S. M. Hosseini, A. H. Shamekhi, and A. Yazdani, "Dynamic modelling and simulation of a polymer electrolyte membrane fuel cell used in vehicle considering heat transfer effects," J. Renewable Sustainable Energy 4, (2012).

[22] G. L. Soloveichik, "Regenerative Fuel Cells for Energy Storage,", Proceedings of the IEEE, vol. 102, no. 6, pp. 964-975, June 2014. 